DOI: http://dx.doi.org/10.18203/2320-1770.ijrcog20171562

\title{
Effect of sildenafil on IUGR
}

\author{
Abha Singh, Abha Daharwal, Avinashi Kujur*, Pragati Awasthi
}

Department of Obstetrics and Gynecology, Pt. J.N.M. Medical College, Raipur, Chhattisgarh, India

Received: 22 March 2017

Accepted: 08 April 2017

*Correspondence:

Dr. Avinashi Kujur,

E-mail: avinashikujur@gmail.com

Copyright: (c) the author(s), publisher and licensee Medip Academy. This is an open-access article distributed under the terms of the Creative Commons Attribution Non-Commercial License, which permits unrestricted non-commercial use, distribution, and reproduction in any medium, provided the original work is properly cited.

\section{ABSTRACT}

Background: IUGR is one of the major culprit of perinatal mortality and morbidity in India, with reported incidence of $21-28 \%$. Objective of present study is to investigate the effect of sildenafil on pregnancies complicated with IUGR and to see its effect on fetal outcome.

Methods: This was a case control study conducted after clearance of Ethical Committee of the Institute from July 2014 to July 2016 in Department of Obstetrics and Gynecology of Dr. B.R.A.M. Hospital, Raipur [C.G.]. All women with pregnancies complicated with IUGR were identified and included in study. According to treatment with Sildenafil women were divided in two groups. Both groups were followed up till delivery and their outcome including birth weight, AC and complications related to IUGR were compared.

Results: IUGR was found to be more prevalent in primi gravidas and women of lower socioeconomic and educational status with low BMI. We found Hypertension in pregnancy as significant causative factor precipitating the IUGR [68\%]. In sildenafil treated group significant $63 \%$ mothers had baby with birth weight $>10$ percentile whereas in sildenafil non treated group only $20 \%$ had $>10$ percentile birth weight. The mean birth weight of Sildenafil treated group was $2594 \mathrm{gm}$ whereas in non-treated group it was $2200 \mathrm{gm}$. In our study, we observed improved AC in $70 \%$ whereas in control group improvement was only in $34 \%$ which was significant.

Conclusions: Sildenafil was found to improves birth weight, abdominal circumference, and reduce the complications related to IUGR.

Keywords: AC, Fetal weight, IUGR, Sildenafil

\section{INTRODUCTION}

Intra uterine growth restriction is one of the major problems of developing country like India. IUGR is one of the major culprit of perinatal mortality and morbity. The reported incidence of IUGR is quite high in India i.e. 21-28\%Asia bears $75 \%$ burden of IUGR. ${ }^{1,2}$ Pregnancy audits have reported that mostly IUGR is not recognized. ${ }^{3}$ Prevention of low birth weight infants becomes an important public health priority in our country. At present no effective treatment is available to treat IUGR. Most of the time expectant management is offered to treat IUGR with only maternal and fetal surveillance. The expectant management includes non specific interventions like rest, stopping work etc. Recently Sildenafil citrate has been shown to increase uterine blood flow and potentiate oestrogen induced vasodilation. The magnitude of the problem is much more in developing countries like India. The internationally recommended IUGR if $>20 \%$, invites urgent interventions to prevent it. Objective of present study is to investigate study the effect of sildenafil on pregnancies complicated with IUGR and to see its effect on fetal outcome.

\section{METHODS}

This was a case control study conducted after clearance of Ethical Committee of the Institute from July 2014 to 
July 2016 in Department of Obstetrics and Gynecology of Dr. B.R.A.M. Hospital, Raipur [C.G.]. All women with pregnancies complicated with IUGR were identified and included in study.

\section{Inclusion criteria}

Inclusion criteria for IUGR:

- Estimated fetal weight $<10$ percentile for gestational age.

- $\mathrm{AC}<5$ percentile for gestational age.

Study group included women taking Sildenafil, control group had women who were not taking Sildenafil.

\section{Exclusion criteria}

Exclusion criteria including women:

- With malformed fetus (structural and genetic abnormalities).

- Any cardiovascular disease.

- On any other vasodilator agent.

Both groups were followed up till delivery and their outcome including birth weight, $\mathrm{AC}$ and complications related to IUGR were compared. The continuous variables were compared by independent student's t test. The categorical variables were compared by chi-square $\left(\chi^{2}\right)$ test. The $p<0.05$ was considered statistically significant.

\section{RESULTS}

IUGR was found to be more prevalent in primi gravidas i.e in $60 \%$ women and most of them were of lower socioeconomic and educational status with poor nutritional levels (Table 1).

Table 1: Socio demographic profile $(n=100)$.

\begin{tabular}{|l|l|}
\hline Variables & Percent \\
\hline Parity wise distribution & \\
\hline Primi & 60 \\
\hline G2 & 34 \\
\hline$>$ G3 & 16 \\
\hline Educational status & \\
\hline Illiterate & 30 \\
\hline Primary & 40 \\
\hline Secondary & 15 \\
\hline Higher & 15 \\
\hline Booked/unbooked status & \\
\hline Booked & 64 \\
\hline Unbooked & 36 \\
\hline Urban/Rural & \\
\hline Urban & 70 \\
\hline Rural & 30 \\
\hline
\end{tabular}

Lack of antenatal check-up or irregular antenatal visits were the most common reasons behind undiagnosed IUGR at term. In our study, Hypertension in pregnancy leading to compromised uteroplacental blood flow was the most common causative factor precipitating the IUGR (68\%) followed by APH (10\%) and maternal diseases (10\%) (Figure 1).

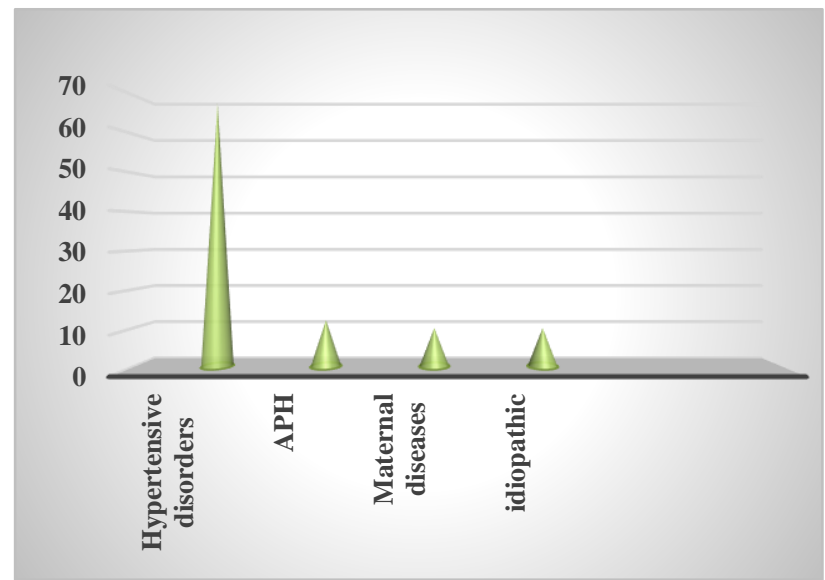

Table 3: Effect of sildenafil on birth weight and abdominal circumference.

\begin{tabular}{|llll|}
\hline Parameters & $\begin{array}{l}\text { Treated } \\
\text { group }\end{array}$ & $\begin{array}{l}\text { Non-treated } \\
\text { group }\end{array}$ & $\begin{array}{l}\text { P } \\
\text { value }\end{array}$ \\
\hline $\begin{array}{l}\text { Birth weight }>10 \\
\text { percentile }\end{array}$ & $63 \%$ & $20 \%$ & 0.001 \\
\hline AC $>5$ percentile & $70 \%$ & $37 \%$ & 0.001 \\
\hline
\end{tabular}

Table 4: Effect of sildenafil on complications related to IUGR.

\begin{tabular}{|lllll|}
\hline \multicolumn{2}{|c|}{$\begin{array}{l}\text { Complications related to IUGR } \\
\text { Percent }\end{array}$} & Percent & \multicolumn{2}{c|}{ p- value } \\
\hline $\begin{array}{l}\text { Pre-term } \\
\text { deliveries }\end{array}$ & 16 & 28 & 0.0 & $\mathrm{~S}$ \\
\hline $\begin{array}{l}\text { Shifted to } \\
\text { nursery }\end{array}$ & 28 & 40 & 01 & \\
\hline $\begin{array}{l}\text { Meconium } \\
\text { aspiration }\end{array}$ & 10 & 16 & 0.0 & $\mathrm{NS}$ \\
$\begin{array}{l}\text { Pre-term } \\
\text { caesarean }\end{array}$ & 08 & 38 & 0.0 & $\mathrm{NS}$ \\
$\begin{array}{l}\text { section } \\
\text { Intrapartum }\end{array}$ & 05 & 12 & 01 & \\
$\begin{array}{l}\text { asphyxia with } \\
\text { metabolic } \\
\text { changes }\end{array}$ & & & 0.0 & $\mathrm{NS}$ \\
\hline \begin{tabular}{l} 
Died \\
\hline
\end{tabular} & 06 & 10 & 76 & \\
\hline
\end{tabular}

In sildenafil treated group $63 \%$ mothers had baby with birth weight $>10$ percentile whereas in sildenafil nontreated group only $20 \%$ had $>10$ percentile birth weight. This was found to be significant ( $p$-value 0.001). The mean birth weight of Sildenafil treated group was $2594 \mathrm{gm}$ i.e. $>2500 \mathrm{gm}$ whereas in non-treated group it was $2200 \mathrm{gm}$ i.e $<2500 \mathrm{gm}$. In our study, we observed 
improved AC in $70 \%$ whereas in control group improvement was only in $34 \%$ which was significant (Table 3).

On observing perinatal outcome in study group, $16 \%$ had preterm delivery whereas in control group more than twice the women i.e. $38 \%$ landed up in pre-term deliveries, which was significant. The incidence of caesarean section for pre-term in study group was $8 \%$ whereas it was significantly higher i.e $38 \%$ in control group. Complications of IUGR like meconium aspiration, intrapartum asphyxia were less in Sildenafil treated women though there was no significant difference.

\section{DISCUSSION}

IUGR is a challenge for the obstetricians. Though there well known maternal, fetal and placental causes of IUGR, but in some women, no risk factors are present. ${ }^{4}$ The incidence of IUGR was found to be $10 \%$ which is lower than its incidence in INDIA. We found IUGR to be more prevalent in primigravida, women belonging to lower socioeconomic and low educational status and ignorant about regular antenatal check-up.

We found hypertension was the leading cause of IUGR in i.e. $68 \%$ of cases. The diagnosis of pre-eclampsia with and without hypertension is significantly associated with IUGR. ${ }^{5}$ Our finding is in discordance with the study at Pakistan. ${ }^{6}$ Their incidence of IUGR in women with PIH was about $28 \%$. Unexplained APH in early weeks of pregnancy, chronic anaemia, renal parenchymal disease, chronic infections, poor nutritional status also form a bulk in causing of IUGR and in about $10 \%$ no cause was identified.

We observed the effect of sildenafil on baby's birth weight. In study group a significant of $63 \%$ babies had birth weight $>10^{\text {th }}$ percentile whereas in control group only $20 \%$ babies had birth weight $>10^{\text {th }}$ percentile. The mean birth weight of sildenafil treated group was $2594 \mathrm{gm}$ whereas in non-treated group it was $2200 \mathrm{gm}$. A smaller trial in women with early onset pre-eclampsia showed a positive effect on birth weight. ${ }^{7}$

$\mathrm{AC}$ is one of the most sensitive indicators of IUGR. In our study, we got improved AC of $70 \%$ in treated group compared to $34 \%$ in non-treated group. The difference between the two was significant. A study by $\mathrm{P}$ von Dadelszen, et al had seen the remarkable effect of sildenafil on AC growth velocity. ${ }^{8}$ Studies have shown that Sildenafil improved fetal well-being in some women by increasing utero placental blood flow. ${ }^{9}$ Both in vivo and in vitro evidence suggests that Sildenafil improves the uteroplacental flow, fetal growth and optimal outcome in IUGR. ${ }^{10}$

Pre-term birth and pre-term cesarean section are unavoidable complications of IUGR. ${ }^{9,10}$ In study group $16 \%$ women had preterm delivery whereas in control group $38 \%$ landed up in pre-term deliveries which was significant. This was in agreement with the study by Janet et $\mathrm{al}^{9}$. The incidence of caesarean section for pre-term in study group was $8 \%$ whereas it was significantly higher i.e $38 \%$ in control group. Other studies also observed that it prolonged the mean gestational age by 1 week and 2 day in severe early onset IUGR. ${ }^{7}$ It was found to decrease the complications of IUGR but also increase the longevity of intrauterine life by making favourable in utero environment thus it indirectly reduces the rate of pre term delivery as well. ${ }^{7,8}$ After evaluating these benefits on IUGR however we did not find any significant difference in Intrapartum asphyxia, meconium aspiration and other complications between the two groups. Studies have shown no evidence of teratogenicity. ${ }^{10}$ However, more evidence is required from randomized control trials to implement its use. ${ }^{11}$

\section{CONCLUSION}

Intrauterine growth restriction (IUGR) remains one of the major challenges in maternity care as well as one of the major causes of perinatal morbidity and mortality. In spite of its major burden on maternal and child health care. We are still in search of a definitive treatment. In present study, Sildenafil was found to improves birth weight, abdominal circumference, and reduce the complications related to IUGR. Sildenafil may be used in selected women with IUGR. It has been found to be safe, cost effective, and free from any adverse effects.

\section{ACKNOWLEDGEMENTS}

The authors are thankful to all the women included in the study, faculty and technical staff of department of Obstetrics and Gynecology, Dr. BRAM Hospital, Pt. J. N. M. Medical College, Raipur (C.G.) India, for their cooperation and support during the entire study period. Authors acknowledge the immense help received from the scholars whose articles are cited and included in references of this manuscript. The authors are also grateful to authors/editors/publishers of all those articles, journals and books from where the literature for this article has been reviewed and discussed.

Funding: No funding sources

Conflict of interest: None declared

Ethical approval: The study was approved by the Institutional Ethics Committee

\section{REFERENCES}

1. Murki S, Sharma D. Intrauterine growth retardation: A review article. J Neonatal Biol. 2014;3:135.

2. Saleem T, Sajjad N, Fatima S, Habib N, Ali SR, Qadir M. Intrauterine growth retardation-small events, big consequences. Ital $\mathrm{J}$ Paediatr. 2011;37:41. 
3. Figueras F, Gardosi J. Intrauterine growth restriction: new concepts in antenatal surveillance, diagnosis, and management. AJOG. 2011;204(4):288-300.

4. Militello M, Pappalardo EM, Ermito S. Angela Diantale Alessandro Cavaliere and Sabina Carrara Obstetric management of IUGR. J Prenatal Medic. 2009;3(1):6-9.

5. Srinivas SK, Edlow AG, Nelf PM, Sammel MD, Andrela CM, Elovitz MA. Rethinking IUGR in preeclampsia; dependent or independent of maternal hypertension. J Perinatol. 2009;29(10):680-4.

6. Zafar H, Naz M, Fatima U, Irshad F. Frequency of IUGR in pregnancy induced hypertension. JUMDC. 2012;3(2):8-13.

7. Samangaya RA, Mires G, Shennan A, Skillen L, Howe D, Mc Leod A, Baker P.N. A randomized double blinded, placebo-controlled study of the phosphodiesterase type 5 inhibitor Sildenafil for the treatment of pre eclampsia. Hypertens pregnancy. 2009;28:369-82.
8. von Dadelszen P, Dwinnell S, Magee LA, Carleton BC, Gruslin A, Lee B et al. Sildenafil citrate therapy for severe early-onset intrauterine growth restriction. BJOG. 2011 Apr;118(5):624-8.

9. Dastjerdi MV, Hosseini S, Bayani L. Sildenafil citrate and uteroplacental perfusion in fetal growth restriction. J Res Med Sci. 2012;17(7):632-6.

10. Ganzevoort W, Alfirevic Z, von Dadelszen P, Kenny L, Papageorghiou A, van Wassenaer-Leemhuis A, et al. STRIDER: sildenafil therapy in dismal prognosis early-onset intrauterine growth restriction-a protocol for a systematic review with individual participant data and aggregate data meta-analysis and trial sequential analysis. Syst Rev. 2014;3:23.

11. Jacobsen JCGC. The necessity of randomized clinical trials. Br J Med Med Res. 2013;3(4);16.

Cite this article as: Singh A, Daharwal A, Kujur A, Awasthi P. Effect of sildenafil on IUGR. Int J Reprod Contracept Obstet Gynecol 2017;6:1806-9. 